\title{
DLNotes2: Anotações Digitais como Apoio ao Ensino
}

\author{
Adiel Mittmann ${ }^{1}$, Roberto Willrich ${ }^{1}$, Renato Fileto ${ }^{1}$, Alckmar Luiz dos Santos ${ }^{2}$, \\ Emanoel C. Pires de Assis ${ }^{2}$, Isabela Melim Borges Sandoval ${ }^{2}$ \\ ${ }^{1}$ Programa de Pós-Graduação em Ciência da Computação - Departamento de \\ Informática e Estatística - Universidade Federal de Santa Catarina (UFSC) \\ Caixa Postal 476 - 88.040-900 - Florianópolis - SC - Brasil \\ ${ }^{2}$ Programa de Pós-Graduação em Literatura \\ Universidade Federal de Santa Catarina (UFSC) - Florianópolis, SC - Brasil \\ \{adiel, willrich, fileto\}@inf.ufsc.br, alckmardcce.ufsc.br, \\ lordemanoel@hotmail.com, isaballoons@hotmail.com
}

\begin{abstract}
This article presents DLNotes2, a tool that supports the creation of structured and semantic (ontology-based) annotations on HTML documents. DLNotes 2 can be easily integrated with Virtual Learning Environments. It allows creating learning activities within which the students' task is to make annotations on certain contents. The Knowledge Base generated in the semantic annotation process can be graphically visualized and edited, allowing both teachers and learners to access the produced knowledge. This article also presents a use case of DLNotes 2 in literature teaching.
\end{abstract}

Resumo. Este artigo apresenta a DLNotes2, uma ferramenta de anotação que suporta a criação de anotações estruturadas e semânticas (baseadas em ontologia) em documentos HTML. A DLNotes 2 pode ser facilmente integrada a Ambientes Virtuais de Aprendizagem. Ela permite a criação de atividades educacionais onde a tarefa dos estudantes é realizar anotações sobre certos conteúdos. A base de conhecimento gerada no processo de anotação semântica pode ser graficamente visualizada e editada, permitindo aos alunos e professores acesso aos conhecimentos produzidos. Este artigo também apresenta um caso de uso da DLNotes 2 no ensino de literatura.

\section{Introdução}

Repositórios Digitais (RDs) oferecendo conteúdos (ou objetos) de aprendizagem têm se expandido nos últimos anos. Porém, a disseminação de conteúdos em RDs não garante a eficiência nos processos de ensino e aprendizado que se utilizam deles. São necessárias novas aplicações aprimorando o uso destes conteúdos nas práticas de ensino. Um bom exemplo dessas aplicações são as ferramentas de anotação, as quais permitem a agregação de informações aos conteúdos e ao mesmo tempo suportam a colaboração entre usuários. Anotações são utilizadas há séculos como uma forma natural para as pessoas associarem comentários e ideias a um documento. Vários especialistas, como [Petri 2005] e [Hwang 2007] demonstraram que o uso de ferramentas de anotação promove melhor desempenho no ensino e na aprendizagem.

Existem basicamente três categorias de anotações digitais. Na primeira estão as anotações não estruturadas, através das quais o usuário pode marcar uma parte do texto e associar um texto livre. Na segunda estão as anotações estruturadas, que têm o corpo da anotação estruturado com campos como título, tipo de anotação e descrição. Na 
última categoria estão as anotações semânticas, que identificam precisamente entidades reconhecidas no conteúdo através de referências às suas descrições formais em ontologias. Uma ontologia contém especificações formais (processáveis por computadores) de conceitos, instâncias e relações semânticas entre eles, que descrevem um domínio de interesse [Roche, 2003].

Este artigo apresenta a DLNotes2, uma ferramenta de anotações estruturadas e semânticas em documentos HTML. Ela foi desenvolvida com base na experiência obtida com uma ferramenta anterior [Rocha, 2009], tratando-se de uma ferramenta completamente reescrita, com novos recursos e sem base na precedente. A DLNotes2 pode ser aplicada a qualquer domínio do conhecimento, graças à possibilidade de importação de ontologias de domínio. Além disso, com a aderência ao padrão IMS LTI (Learning Tools Interoperability) [IMS Global, 2012], ela pode ser integrada a qualquer sistema compatível com esse padrão, tal como o ambiente virtual de aprendizagem Moodle.

A DLNotes2 permite a criação de atividades de anotação, em que o professor pode definir um conjunto de conteúdos e os tipos de anotação que os alunos podem realizar no contexto de uma atividade. Graças ao suporte do IMS LTI, o professor pode cadastrar a atividade criada na DLNotes 2 em um ambiente de ensino qualquer que adote tal padrão. Neste artigo demonstramos o uso da DLNotes 2 em atividades de ensino na área de Literatura na Universidade Federal de Santa Catarina. Para tal, a DLNotes2 foi integrada ao Moodle. Uma característica importante que diferencia a DLNotes2 de outras ferramentas de anotação é a possibilidade de geração de anotações semânticas que identificam entidades nomeadas no texto estudado e associam cada uma delas a conceitos especificados em uma ontologia de domínio. Produzindo estas anotações semânticas, professores e alunos colaboram na criação de indivíduos em uma base de conhecimento ( $\mathrm{KB}$ - Knowledge Base). Tais anotações, e a KB, podem auxiliar na análise e classificação de conteúdos objetos das atividades educacionais.

\section{Trabalhos Relacionados}

Existem diversas experiências do uso de ferramentas de anotações em RDs e como suporte a atividades de ensino. A maior parte dessas ferramentas não permite a criação de anotações semânticas, como é o caso de [Gayoso-Cabana 2012], [Nichols 2000] e [Wang, 2011]. Esta categoria de anotação contribui em três aspectos: ontologias possibilitam uma representação robusta de entidades e seus relacionamentos; ontologias permitem a troca de conhecimento entre diferentes sistemas pelo provimento de uma conceitualização compartilhada; ontologias e tecnologias da Web Semântica permitem representar a semântica dos dados de maneira processável por máquina, possibilitando o reconhecimento de conceitos para processos de inferência e busca semântica.

Outras ferramentas suportam anotação usando linguagens de marcação. Porém, isso só gera anotações livres e/ou estruturadas e não uma base de conhecimento. MADCOW 2.0 [Avola 2010] é exemplo de tal categoria de ferramenta de anotação.

Algumas ferramentas de anotações são voltadas ao ensino. Por exemplo, [Nokelainen 2004] propõe uma ferramenta que permite associar comentários ao texto, na forma de anotações livres, porém sem semântica formal. @ Note [Gayoso-Cabana 2012] permite a criação de anotações estruturadas em documentos do Google Books. A exemplo da DLNotes2, ela oferece recursos para criar atividades educacionais de 
anotação. Na definição de uma atividade, o professor pode especificar restrições quanto à visibilidade das anotações, aos privilégios de criação e edição de anotações e esquemas de anotações usados nas atividades. Esses esquemas são na realidade taxonomias usadas para categorizar anotações, sem torná-las anotações semânticas. [Gerber 2010] propõe um sistema de anotação que é uma extensão do navegador Firefox. Este sistema permite a geração de anotações estruturadas, com a possibilidade de ligação semântica com uma ontologia de domínio de Literatura. Um aspecto negativo deste sistema é a necessidade do usuário instalar uma versão específica de um browser, além de utilizar uma ontologia única, portanto, limitada ao domínio de Literatura.

A ferramenta DLNotes2 diferencia-se das outras por ser baseada em uma ontologia de domínio, que pode ser alterada dependendo da área e até mesmo da atividade na qual seja usada. Diferente das propostas existentes, a DLNotes2 não usa ontologias simplesmente para criar anotações semânticas. Os próprios usuários da ferramenta colaboram na construção da KB, via a geração de indivíduos (instâncias de conceitos) na KB para as anotações semânticas. Além disso, o usuário tem à disposição uma visão gráfica da $\mathrm{KB}$ criada, possibilitando a visualização e a análise do conhecimento nela contido. Finalmente, outras ferramentas de anotações semânticas existentes oferecem recursos para facilitar a sua integração com outros sistemas, como RDs, portanto não poderiam ser facilmente empregadas para a construção de $\mathrm{KB}$ em repositórios digitais.

\section{DLNotes2: Uma Ferramenta de Anotação Voltada ao Ensino}

Esta seção apresenta a DLNotes2, uma ferramenta de anotação estruturada e semântica de documentos HTML. Essa ferramenta pode ser aplicada em dois cenários: como ferramenta integrada a RDs, permitindo que os usuários façam anotações públicas e privadas nas obras disponibilizadas; e como uma ferramenta de apoio ao ensino, oferecendo recursos para o professor criar atividades envolvendo anotações digitais. Este artigo foca neste segundo cenário, em que a DLNotes2 pode ser utilizada para melhorar a experiência de alunos e professores, facilitando tanto a leitura de textos em sala de aula quanto a sua utilização em exercícios práticos.

A DLNotes2 foi implementada na linguagem PHP com o framework CodeIgniter sobre o sistema de gerenciamento de bancos de dados MySQL. As ontologias de domínio e as bases de conhecimento produzidas pelos usuários são também armazenadas no MySQL. Contudo, a DLNotes2 oferece mecanismos para exportar e importar dados no formato RDF. No lado do cliente, as linguagens usadas foram HTML e JavaScript, além das bibliotecas jQuery e D3.js (http://d3js.org).

\subsection{Importação de Ontologias}

A DLNotes2 oferece recursos para a importação de ontologias, o que permite sua adaptação a domínios com conceitos e relações específicos. $\mathrm{Na}$ versão atual da ferramenta, as ontologias devem ser representadas utilizando RDFS (RDF Schema), podendo ser criadas com editores de ontologias como Protégé (http://protege.stanford.edu). Alternativamente, a DLNotes2 oferece mecanismos para importar mapas mentais especificados através da ferramenta FreeMind (http://freemind.sourceforge.net/wiki/index.php/Main_Page). Os mapas mentais são convertidos em ontologias automaticamente pelo DLNotes2. Ontologias criadas com o FreeMind dispõem de um conjunto limitado de recursos quando comparados a todo o 
potencial do RDFS, o que permite que até mesmo usuários leigos criem ontologias, simplificadas porém úteis para estes usuários.

\subsection{Geração de Atividades de Anotação}

Os usuários administradores da DLNotes2, entre os quais os professores, podem criar atividades de anotação. Na DLNotes2, uma atividade de anotação é uma modalidade de tarefa dada a alunos cujo meio de realização é através da criação de anotações sobre conteúdos informados pelo professor. Os objetivos específicos de tal tarefa podem ser os mais variados possíveis, como analisar um conteúdo, identificar seus conceitos e relacionamentos, criticar ou revisar um conteúdo, ou apenas comentar as suas partes.

Uma atividade de anotação é definida por: um nome próprio que identifica a atividade; um conjunto de documentos do RD (identificados por URLs); a ontologia de domínio a ser considerada na atividade; a relação de moderadores e estudantes envolvidos; e diversos parâmetros que afetam a maneira como os usuários da DLNotes2 interagem com esses documentos.

Os estudantes envolvidos em uma atividade podem ser adicionados manualmente através da interface de administração do DLNotes2, ou podem ser incluídos automaticamente via IMS LTI (visto na seção 3.3). Em termos de parâmetros da atividade, o professor pode definir as permissões dos usuários moderadores e estudantes. Essas permissões incluem os direitos para criar anotações, os tipos de visibilidade de anotações permitidos (anotações públicas que são visíveis a todos os envolvidos na atividade, anotações visíveis ao criador e ao moderador, ou anotações privadas que são visíveis apenas ao criador), e os tipos de anotações permitidos (estruturadas e semânticas).

\subsection{Integração com ambientes virtuais de Aprendizagem}

Um dos requisitos de projeto do DLNotes2 é a capacidade de integração com ambientes virtuais de aprendizagem. Para alcançar tal objetivo, foi adotado o protocolo IMS Basic LTI (Learning Tools Interoperability - http://www.imsglobal.org/lti). O IMS LTI é um padrão permitindo a interoperabilidade de plataformas como LMS (Learning Management Systems), portais, ou outros ambientes educacionais, chamados de Consumidores LTI, com ferramentas externas chamadas Produtores LTI. O IMS Basic LTI é a versão mais simples do IMS LTI, que permite a um Provedor LTI invocar um Consumidor LTI, mas nenhum resultado da atividade é retornado ao consumidor.

Na terminologia LTI, a DLNotes2 é um Produtor LTI, que pode ser lançada como uma ferramenta externa em qualquer Consumidor LTI. Através da interface de criação da atividade de anotação, o professor pode acessar o URL de lançamento da ferramenta, a chave do consumidor, que identifica a atividade específica que o usuário vai acessar, e a senha compartilhada da atividade. De posse destas informações, basta o professor criar uma atividade do tipo ferramenta externa no Consumidor LTI utilizado no seu curso.

Graças aos parâmetros passados pelo LTI, o usuário autenticado no Consumidor LTI é automaticamente autenticado na DLNotes2. Assim, o professor pode criar uma atividade de anotação com a DLNotes2 e adicioná-la a seu curso no Moodle, usando a modalidade de atividade "ferramenta externa". Quando o aluno se autentica no Moodle e acessa a DLNotes como ferramenta externa, ele também se autentica na DLNotes2. 


\subsection{Interface de Anotações}

O usuário tem duas formas de acesso a um documento HTML no contexto de uma atividade de anotação. A primeira forma é o acesso Web ao DLNotes2 em que o usuário, após sua autenticação, terá acesso a todas as atividades de anotação das quais participa. A segunda forma é via um Consumidor LTI, como o Moodle, onde o usuário simplesmente clica sobre a tarefa definida no seu curso.

Quando um usuário (seja ele estudante ou moderador) acessa um documento HTML no contexto de uma atividade de anotação, ele pode visualizar o documento original acrescido das anotações já criadas, conforme exemplificado na Figura 1. Os trechos anotados (alvos das anotações) são demarcados por colchetes e realçados pelo sublinhado e pelo ícone à sua esquerda indicando o tipo de anotação. Vários tipos de anotações estruturadas foram definidos, incluindo Comentário, Recomendação, Tarefa, Exemplo, Explicação, Pergunta e Ver Também. O tipo de anotação semântica é único.

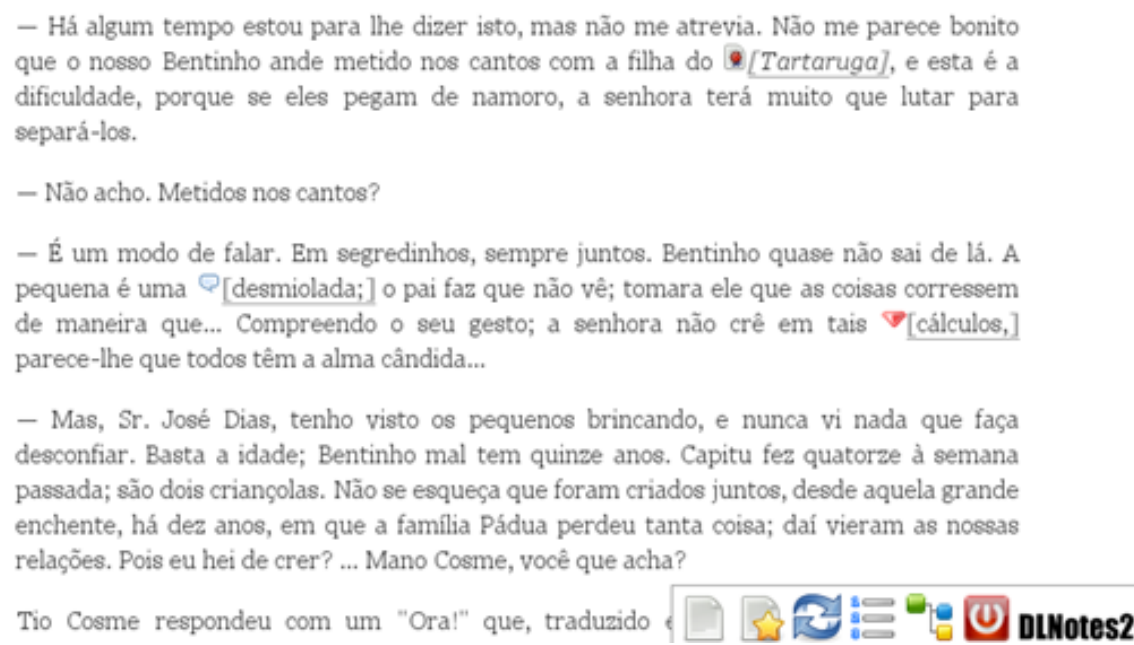

- Há algum tempo estou para lhe dizer isto, mas não me atrevia. Não me parece bonito que o nosso Bentinho ande metido nos cantos com a filha do [Tartaruga], e esta ê a dificuldade, porque se eles pegam de namoro, a senhora terá muito que lutar para separá-los.

- Não acho. Metidos nos cantos?

- É um modo de falar. Em segredinhos, sempre juntos. Bentinho quase não sai de lá. A

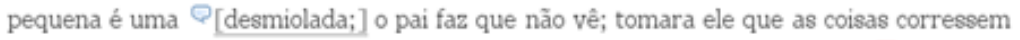
de maneira que... Compreendo o seu gesto; a senhora não crê em tais $\nabla$ [cálculos,] parece-lhe que todos têm a alma cândida...

- Mas, Sr. José Dias, tenho visto os pequenos brincando, e nunca vi nada que faça desconfiar. Basta a idade; Bentinho mal tem quinze anos. Capitu fez quatorze à semana passada; são dois criançolas. Não se esqueça que foram criados juntos, desde aquela grande enchente, há dez anos, em que a familia Padua perdeu tanta coisa; daí vieram as nossas relações. Pois eu hei de crer? ... Mano Cosme, você que acha?

Tio Cosme respondeu com um "Ora!" que, traduzido $D$ त3

\section{Figura 1. Interface do DLNotes2.}

Para criar uma anotação, o usuário primeiramente seleciona a parte do texto a ser anotada, ou seja, o alvo da anotação. Para fazê-lo, basta clicar na palavra inicial do trecho a anotar e, em seguida, onde deve terminar. Assim que o usuário determina o alvo da anotação, abre-se a interface de seleção do tipo de anotação e visibilidade. Nessa interface, apresentada na Figura 2, o usuário pode indicar se a anotação é estruturada, chamada Livre para facilitar o entendimento do usuário, ou semântica. As opções de visibilidade são três: Privada - visível apenas ao usuário criador da anotação; Pública - permite que todos os usuários acessando o documento vejam a anotação; Moderador - permite apenas o autor e os moderadores visualizarem a anotação.

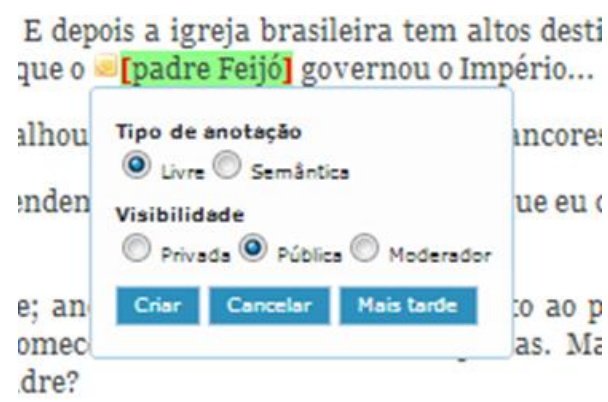

Figura 2. Menu de seleção do tipo da anotação e a sua visibilidade. 
Ao selecionar o tipo de anotação estruturada, o usuário visualiza a interface de criação de anotação estruturada, vista na Figura 3. Anotações deste tipo são estruturadas em três partes: a definição do tipo de anotação; um título opcional para a anotação; e o corpo propriamente dito, na forma de um texto formatado. Para o usuário visualizar o corpo de uma anotação, basta clicar no ícone da anotação para que seja aberta na interface de leitura de anotação, ilustrada na Figura 4. Para cada anotação é criado um fórum de discussão para diversos propósitos, como comentários do professor ou discussões entre estudantes e professores.

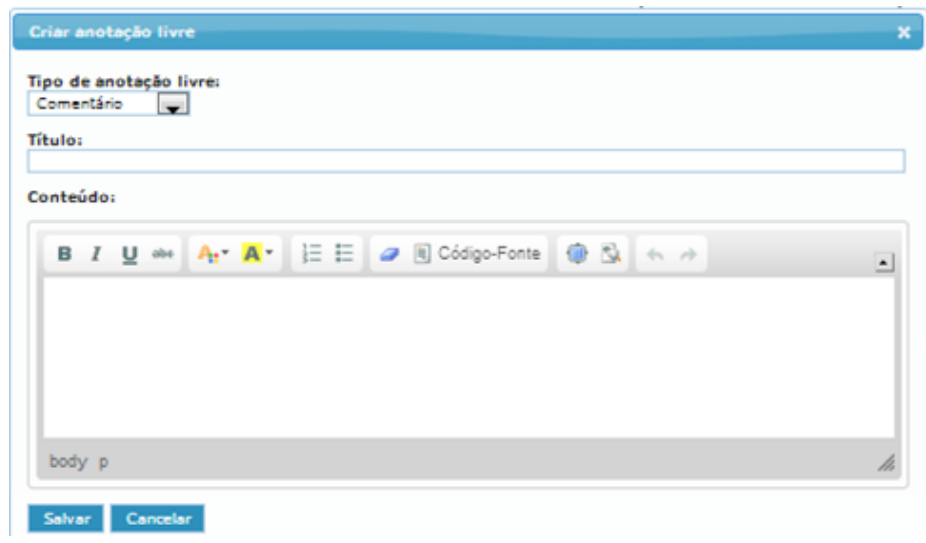

Figura 3. Interface de criação de anotação estruturada.

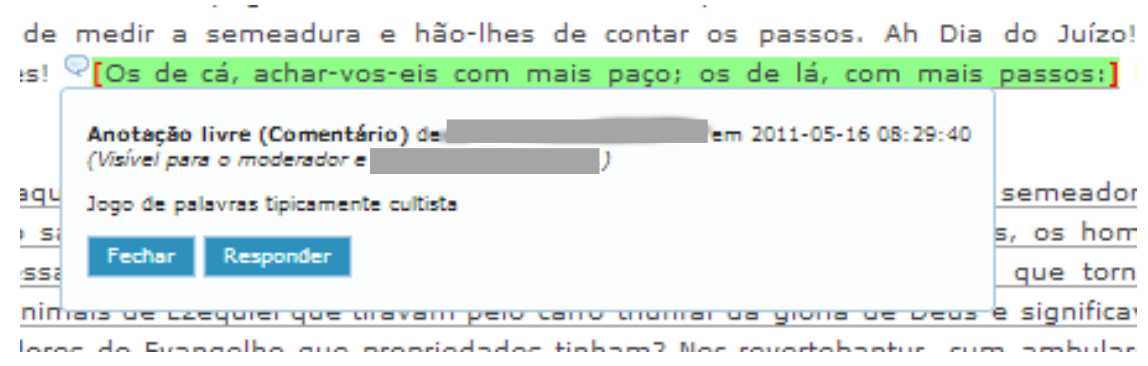

Figura 4. Leitura da anotação estruturada.

Caso o usuário opte por criar uma anotação semântica, a DLNotes2 apresenta a interface de criação de anotação semântica, apresentada na Figura 5. À esquerda dessa interface é apresentada a hierarquia de classes da ontologia de domínio, na qual o usuário deve selecionar a classe da ontologia que ele deseja associar ao alvo da anotação. Selecionada a classe, é aberta a parte direita da interface para o usuário criar ou escolher uma instância da classe selecionada e relacioná-la ao trecho anotado no texto. Por exemplo, em uma obra literária o usuário pode selecionar o nome da personagem e criar uma anotação semântica sobre este trecho. $\mathrm{O}$ usuário pode definir que a classe é Personagem e em seguida definir os atributos da personagem (nome, papel, relações com outras personagens, etc.). Assim, ele cria uma nova Personagem na KB. Nem toda classe da ontologia se refere a indivíduos. Algumas servem para outros tipos de anotação semântica. Por exemplo, o usuário pode associar uma anotação semântica a um trecho de texto indicando que o alvo da anotação é um Provérbio.

A criação de instâncias na KB possibilita a sua fácil e precisa localização. Por exemplo, quando o usuário cria uma anotação semântica que se refere a uma personagem, ele pode recuperá-la digitando parte do seu nome. Ademais, um indivíduo que possui um identificador (chave) pode ser associado a outro por meio de uma relação. É possível, por exemplo, especificar que uma personagem é filha de outra. As 
relações que podem ser estabelecidas entre indivíduos de cada classe são definidas na ontologia de domínio. Na Figura 5, nota-se que indivíduos da classe Personagem possuem uma relação chamada tem relações pessoais com, que especifica que uma personagem tem relações pessoais com outras personagens. De acordo com a ontologia dessa figura, um animal poderia, por exemplo, ter relações pessoais com um objeto.

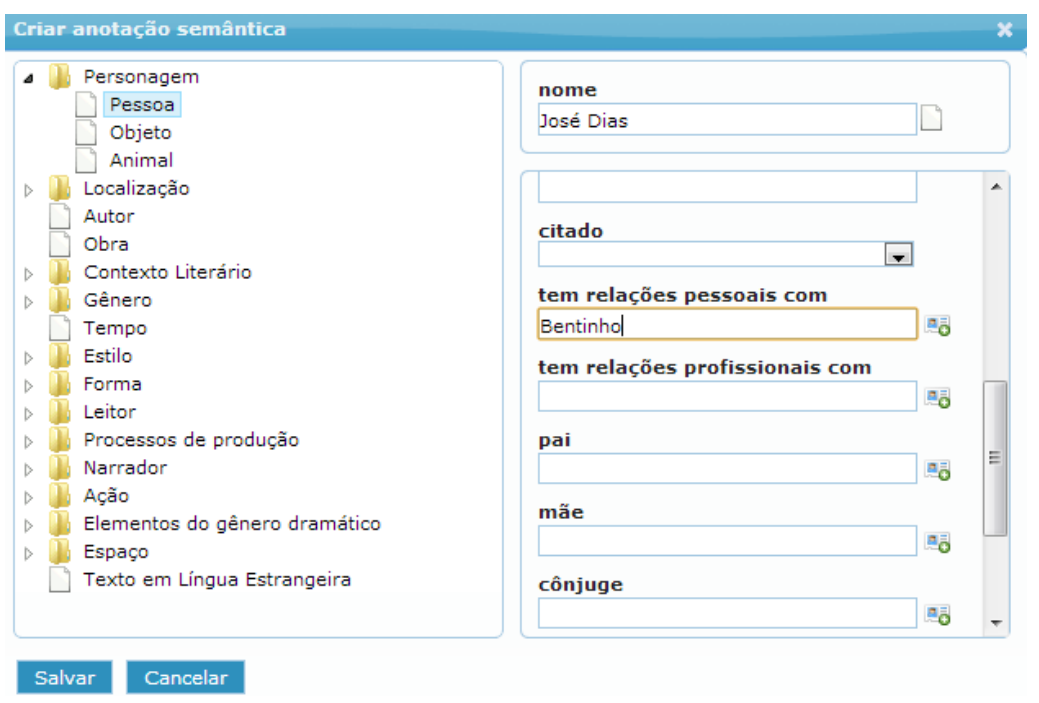

Figura 5. Interface de criação de anotação semântica.

Vale ressaltar que as anotações realizadas pelos usuários não modificam o documento HTML original. Elas apenas definem trechos específicos dentro do documento e os associam a informações adicionadas pelo usuários, que são armazenadas à parte, na KB. Além disso, a KB pode conter anotações realizadas no contexto de diferentes atividades de anotação, por diferentes usuários (estudantes e moderadores). O documento pode até mesmo ser alterado caso necessário, sem perda das anotações efetuadas, pois a DLNotes2 possui uma funcionalidade de migração de anotações que localiza o trecho anotado mesmo após modificações no documento.

\subsection{Interface de Visualização da Base de Conhecimento}

Alunos e professores colaboram na construção de uma KB durante o processo de anotar semanticamente um documento. Para os usuários visualizarem a KB, a DLNotes2 oferece uma interface gráfica para visualização as instâncias da KB relacionadas ao conteúdo em anotação, como ilustrado na Figura 6.

A interface de visualização gráfica da $\mathrm{KB}$ permite definir filtros para visualização apenas de indivíduos de determinadas classes. Com o uso de filtros, tanto o professor quanto os alunos podem gerar visualizações específicas. No exemplo da Figura 6, apenas as personagens e localizações gráficas de uma obra literária foram anotadas. Nesta figura, as localizações foram filtradas, para evidenciar a existência de 5 personagens e das relações entre elas. Os ícones correspondentes às personagens podem ser arrastados e reposicionados na tela. Quando o usuário leva o cursor até um ícone, as associações com o indivíduo correspondente são destacadas para que o usuário possa explorar melhor a KB. Pode-se também apresentar o encadeamento de eventos ao longo de uma linha temporal, através das instâncias da classe Fato criadas pelos usuários e então ligar esses fatos às personagens que participaram de sua execução. 
A interface de visualização da $\mathrm{KB}$ não se limita a exibir indivíduos. Ela também permite a edição da KB. A Figura 7 mostra o menu ao qual o usuário tem acesso quando clica com o botão secundário do mouse sobre um indivíduo. Através deste menu, o usuário pode editar parâmetros do indivíduo, excluí-lo, instanciar outro indivíduo da mesma classe ou adicionar uma das associações permitidas para a classe do indivíduo.

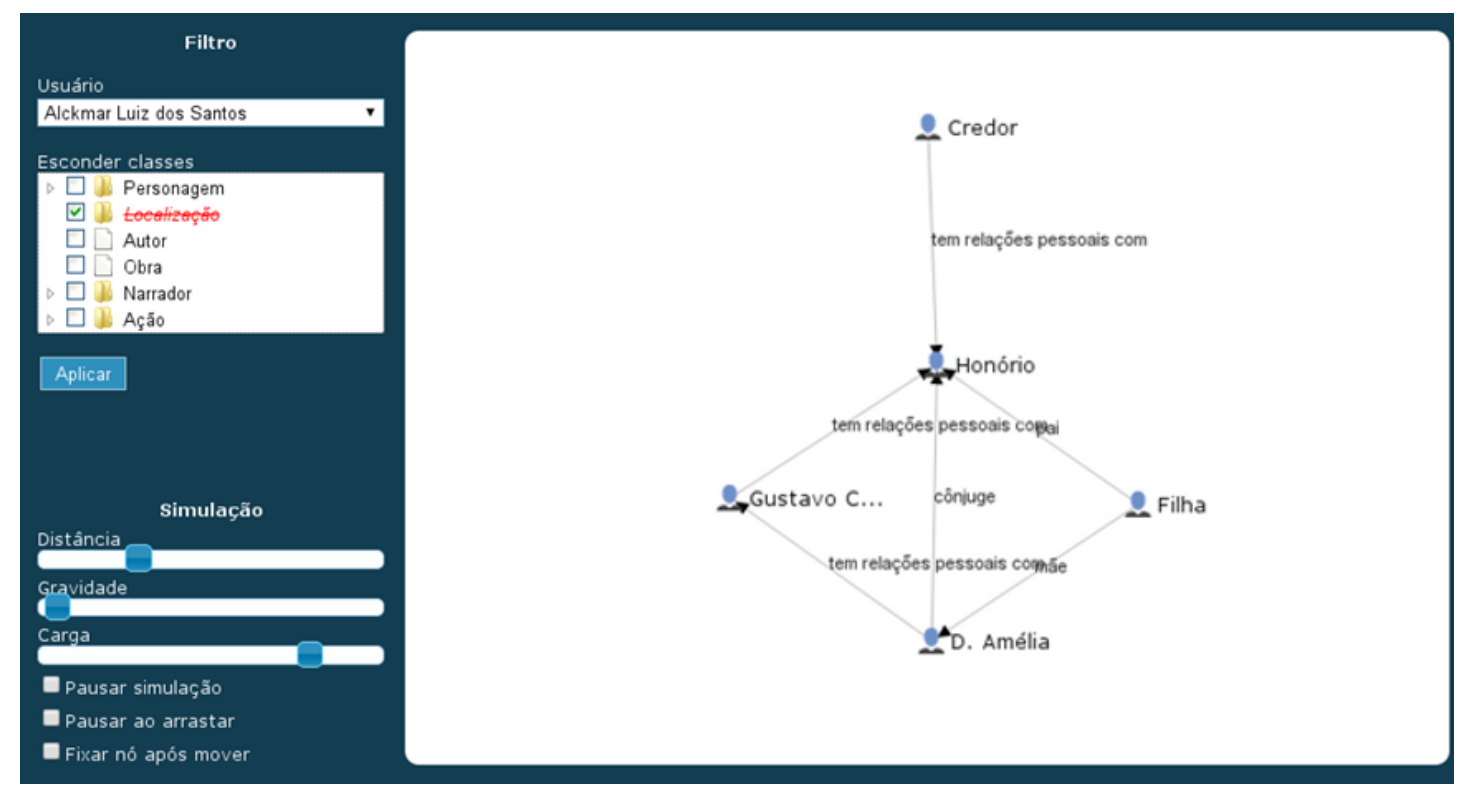

Figura 6. Visualização gráfica da KB.

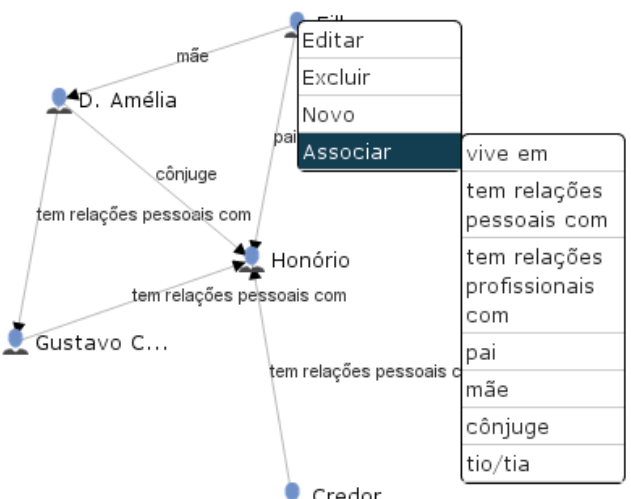

Figura 7. Menu de contexto de um indivíduo.

\section{Caso de Uso da DLNotes2 no Ensino de Literatura}

Para ilustrar a utilização da DLNotes2 como ferramenta de apoio ao ensino, esta seção apresenta um caso de seu uso no ensino de Literatura Brasileira. Para utilizar a DLNotes2 no ensino de literatura, foi desenvolvida uma ontologia para o domínio de análise literária, isto é, a decomposição de um texto em suas partes constitutivas, para perceber o valor e o relacionamento que guardam entre si e para melhor compreender, interpretar e sentir a obra como um todo completo e significativo. Tal ontologia contém classes que permitem categorizar indivíduos (instâncias), como Personagem (com subclasses Pessoa, Objeto e Animal), Local (com subclasses como Bairro, País ou mesmo Planeta) e Ação (com diversas subclasses, como Clímax e Fato). Além destas, existem várias classes usadas para marcar semanticamente trechos do texto, tais como 
Gênero (com uma vasta hierarquia de subclasses, incluindo Poema/Narrativo e Sermão) e Estilo (com subclasses como Metáfora e Anacoluto).

A DLNotes2 tem sido utilizada há 2 anos em disciplinas de graduação e pósgraduação como Literatura Brasileira, Estudos Literários e Teoria do Verso na Universidade Federal de Santa Catarina. Os alunos são incentivados a ler e anotar os textos relevantes às disciplinas, que vão desde pequenas seleções de poemas até obras literárias completas. As anotações feitas pelo professor podem ter como objetivo explicar alguma passagem obscura, anexar algum material adicional que enriqueça a leitura ou solicitar aos alunos que façam alguma tarefa. Os alunos podem então discutir as anotações do professor ou então criar novas anotações. Após encerrar o prazo da tarefa, o professor (ou então outro usuário com poder de moderador na atividade) pode utilizar o relatório interativo de anotações para ver quais anotações cada aluno fez.

As anotações semânticas foram especificamente úteis para a categorização de elementos contidos nos documentos. Desta forma, este tipo de anotação permite aos usuários colaborarem na construção de um conhecimento explícito, que pode atualmente servir para realização de análises/interpretação do documento de maneira manual.

Além de interagir com as anotações feitas pelo professor, os alunos podem fazer suas próprias anotações e, muitas vezes, a tarefa como um todo consiste em anotar um texto com comentários, perguntas e observações pertinentes. Nesses casos, a quantidade e a qualidade das anotações variam muito de um aluno para outro. Para se ter uma ideia mais precisa de como os alunos estão anotando os textos, uma avaliação foi realizada nas anotações feitas em três obras literárias. Foram analisadas 982 anotações no total, as quais foram produzidas por uma turma de 53 alunos em que uma média de 23 optou por utilizar a ferramenta. Essa análise classificou o tipo das anotações em 5 categorias: $65,7 \%$ foram comentários, $19,3 \%$ explicações, $7,7 \%$ perguntas, $4,3 \%$ dúvidas e $3,3 \%$ pesquisa. Percebe-se que, apesar da maioria das anotações serem comentários, ainda assim uma proporção significativa buscou trazer uma explicação para o que lia (19,3\%). Percebeu-se, ainda, que as anotações feitas nas últimas obras anotadas foram melhores que as feitas nas primeiras obras, o que indica que houve um processo de melhoria na qualidade da leitura do aluno.

Em cada atividade de anotação, entre anotações livres e semânticas, com pequenas variações, os alunos criaram uma média de 12,5 anotações cada um. Em termos qualitativos, o professor envolvido constatou uma melhora expressiva na capacidade de leitura e de reflexão sobre a obra literária. Não foram apenas as anotações que, na maioria, revelaram perspicácia e interesse, mas as discussões em sala-de-aula melhoraram sensivelmente.

\section{Conclusão}

A ferramenta de anotação de conteúdos digitais aqui proposta, a DLNotes2, oferece à aprendizagem eletrônica recursos para apoiar o ciclo de produção e agregação de conhecimento. Ela permite a construção e a associação de conhecimento adicional ao conteúdo lido, na forma de anotações estruturadas e semânticas, além de discussões sobre o conteúdo das obras e das anotações. A KB, construída de maneira colaborativa via geração de anotações semânticas sobre os conteúdos, pode ser visualizada pelos usuários, de modo a facilitar o entendimento do conhecimento produzido. 
Entre os trabalhos futuros estão: (i) a importação e exportação de anotações no formato aberto W3C Open Annotation [W3C, 2013], (ii) implantação de mecanismos de colaboração para construção e validação conjunta da KB; (iii) a criação de serviços de buscas semânticas baseadas no conhecimento adquirido nos esforços de anotação, (iv) o desenvolvimento de um módulo para criação de regras de inferência sobre a KB gerada, e (v) o tratamento de conhecimento inconsistente e anotações incoerentes.

\section{Agradecimentos}

Este trabalho foi desenvolvido no contexto do projeto PRONEX Autores, obras e acervos literários catarinenses em meio digital, financiando pela FAPESC-CNPq.

\section{Referências}

Avola, D., Bottoni, P., Levialdi, S. Panizzi, E. (2010) "Interacting annotations in MADCOW 2.0". Intl. Conf. on Advanced Visual Interfaces, p. 389-390.

Gayoso-Cabana, J. et al (2012) "A flexible model for the collaborative annotation of digitalized literary Works". Intl. Conf. on Digital Humanities, Hamburg. http://www.dh2012.uni-hamburg.de.

Gerber, A. Hyland, A. Hunter, J. (2010) “A Collaborative Scholarly Annotation System for Dynamic Web Documents - a Literacy Case Study”. LNCS 6102, p. 29-39.

Hwang, W., Wang, C. and Sharples, M. (2007) "A study of multimedia annotation of web-based materials", Computers and Education, 48(4), p. 680-99.

IMS Global (2012) "IMS Global: Learning Tools Interoperability (LTI)". http://www.imsglobal.org/toolsinteroperability2.cfm.

Nichols, D. M., et al. (2000) "DEBORA: Developing an interface to support collaboration in a digital library". LNCS 1923, p. 239-248.

Nokelainen, P., Miettinen, M., Kurhila, J., Floréen, P. \& Tirri, H. (2005) “A shared document-based annotation tool to support learner-centred collaborative learning". British Journal of Educational Technology, 36, 5, 757-770.

Petri, N., Miikka, M., Jaakko, K., Patrik, F. and Henry, T. (2005) "A shared documentbased annotation tool to support learner-centred collaborative learning", British Journal of Educational Technology, 36 (5), p. 757-70.

Rocha, T. R. da, Willrich, R., Fileto, S. Tazi, S. (2009) "Supporting Collaborative Learning Activities with a Digital Library and Annotation". Education and Technology for a Better World IFIP Advances in Information and Communication Technology, Vol. 302, pp 349-358.

Roche, C. (2003) "Ontology: a survey”. 8th Symposium on Automated Systems Based on Human Skill and Knowledge (IFAC)", Göteborg, Sweden.

W3C (2013). Open Annotation Community Group, http://www.w3.org/community/openannotation/.

Wang, Y.C., Chen, C.M., Hong, C.M., UHuang, P.H. (2011) "Digital library with reading annotation tool for supporting effective reading learning" International Conference on Electrical and Control Engineering (ICECE), p. 6532-6536. 